\title{
Paraphenylenediamine and related chemicals as allergens responsible for allergic contact dermatitis
}

Joanna Bacharewicz-Szczerbicka, Teresa Reduta, Anna Pawłoś, Iwona Flisiak

Department of Dermatology and Venerology, Medical University of Bialystok, Bialystok, Poland

Submitted: 28 November 2017; Accepted: 28 March 2018; Online publication: 18 July 2019

Arch Med Sci 2021; 17 (3): 714-723

DOI: https://doi.org/10.5114/aoms.2019.86709

Copyright @ 2019 Termedia \& Banach

\section{Abstract}

Introduction: Paraphenylenediamine (PPDA) is a chemical with strong sensitizing properties used for dyeing of hair and textiles. Paraphenylenediamine can cross-react, resulting in allergy to other related compounds. The prevalence of PPDA sensitization varies widely. The objectives were to assess the frequency of positive patch test reactions to PPDA and related chemicals among patients with allergic contact dermatitis (ACD) and to analyze them regarding their clinical pattern, occupation and cross-reactions.

Material and methods: The sociodemographic and clinical data of patients with positive patch tests to PPDA, $N$-isopropyl- $N$-phenyl-4-phenylenediamine (IPPD), ethylenediamine (EDA), triethylenetetramine (TETA) and toluene-2,5diamine (TDA) were analyzed. The frequency, strength and cross-reactions with other chemicals were assessed.

Results: Of 4087 ACD patients patch-tested between 2006 and 2015, positive reactions to PPDA and other amines were found in 166 (4.1\%). The occupational character of PPDA allergy was established in $34.3 \%$ of patients. Personal history of atopy was reported by $36.7 \%$ of patients. In $98 \%$ of those examined, allergy presented as ACD, most frequently affecting hands. Hypersensitivity to PPDA was diagnosed in $77.1 \%$, to IPPD in $20.5 \%$, to TDA in $6 \%$, to TETA in $1.2 \%$, and to EDA in $0.6 \%$ of cases. The patients with an extremely strong PPDA reaction significantly more frequently showed reactions to other para group chemicals, especially to benzocaine.

Conclusions: Paraphenylenediamine was a major cause of contact allergy of diverse clinical picture more often affecting women, especially with atopy. Every fifth PPDA-allergic person exhibited hypersensitivity to other related compounds. Strong reactions to PPDA increased the risk of cross-reactions.

Key words: occupation, contact allergy, paraphenylenediamine, cross-reactivity.

\section{Introduction}

Paraphenylenediamine, 1,4-diaminobenzene (PPDA) is an aromatic amine used for permanent dyeing of hair, furs and textiles since the end of the nineteenth century. Due to its strong sensitizing properties, PPDA was banned for several dozen years in some European countries, and it is currently allowed in the concentration regulated by the European Union (EU) law [1].

In the majority of cases, PPDA is responsible for delayed type hypersensitivity reactions, less frequently for immediate type allergy [2-4]. In rare cases it may cause intravascular hemolysis leading to renal insufficiency [5].

\author{
Corresponding author: \\ Teresa Reduta PhD, MD \\ Department of Dermatology \\ and Venereology \\ Medical University \\ of Białystok \\ 14 Zurawia St \\ 15-540 Bialystok, Poland \\ Phone: +48 857409570 \\ E-mail: treduta@umb.edu.pl
}


Hair dyes are the main source of PPDA. Others include textile or fur pigments, cosmetics, tattoos, photographic developers, photocopying and printing inks, black rubber, oils and gasoline $[6,7]$.

Paraphenylenediamine may show cross-reactions to other chemicals belonging to the socalled para group that contains an amine group on a benzene ring at the para position, which may also cause allergy to other related compounds [8].

The prevalence of hypersensitivity to PPDA among allergic contact dermatitis (ACD) patients in Europe is estimated to be $1.5-6 \%[9,10]$ and has been rising due to frequent hair dying and the fashion for tattooing [8, 11].

The objectives were to assess the frequency of positive patch test reactions to PPDA and related chemicals in patients with allergic contact dermatitis and to analyze them in relation to sociodemographic characteristics of patients, clinical pattern of allergy, patient's occupation and cross-reactions to other related compounds.

\section{Material and methods}

Patch test results of 4087 ACD patients treated in the Department of Dermatology and the outpatient clinic between 2007 and 2015 were retrospectively assessed. The medical documentation of patients with positive patch test results with PPDA and related chemicals were selected and a chart review was performed. The data collected included age, sex, social background, occupation, duration of disease, presence of atopy in family and/or in patient, the source of dermatitis and its association with occupational activity, clinical characteristics of skin lesions, diagnosis and treatment. Charts with incomplete data were not assessed. Patients treated with immunosuppressive agents including corticosteroids during 3 weeks before patch testing were excluded from the analysis. Patients with doubtful reactions at the second reading were also excluded. Patients with positive patch tests with allergens from the para group such as caines or parabens but with negative tests with PPDA and its derivatives were not considered in the analysis. Therefore 166 subjects participated in the study. In assessment of cross-reactions in patients allergic to PPDA and simultaneous reaction to other allergens from the para group the patients with the highest grade of reaction to PPDA were considered as the primary sensitized.

Data of patients with positive patch test reactions to PPDA (1.0\%, pet), $N$-isopropyl- $N$-phenyl4-phenylenediamine (IPPD) $(0.1 \%$, pet) from the standard series, to ethylenediamine (EDA) $(1.0 \%$, pet) and triethylenetetramine (TETA) $(0.5 \%$, pet) from the epoxy series, and toluene-2,5-diamine (TDA) (1.0\%, pet) from the hairdressers' series were analyzed. All patients were tested using contact allergens of the European Standard Series (Chemotechnique Diagnostics, Sweden); and 38 patients additionally with: epoxy series (5 persons), cosmetics ( 26 persons), medicaments (6 patients) and plants (4 patients) according to the patient's history and clinical appearance of skin lesions. The patch test results were read twice, 30 min after antigen removal (day 2) and $48 \mathrm{~h}$ after the first reading (day 4), and categorized according to the International Contact Dermatitis Research Group criteria. Results graded as at least + in the second reading were considered for analysis.

The sociodemographic data, clinical manifestations of contact allergy, family and personal history of atopy and relationship between allergy and occupational work were assessed. The relationship between occupational work and allergy was established on the basis of a detailed history (taking into account the degree of occupational exposure to allergen, the relationship between skin lesion duration and exposure to allergen), clinical appearance and distribution of skin lesions. The association with occupational work was stated as proven or probable. The frequency of positive patch test reactions to particular amines, their intensity and cross-reactivity with other related chemicals were determined.

The study was approved by the ethical committee of the Medical University of Bialystok.

\section{Statistical analysis}

Statistical analysis was performed using Statistica v.12.5. (StatSoft Inc., Tulsa, Oklahoma, USA). Descriptive information was presented in the tables as numbers with percentages. To compare sociodemographic and clinical data as well as the prevalence of patch test results the score test for two population proportions was used. Parametric data were compared using Student's t test for unpaired data. A $p$-value $<0.05$ was considered statistically significant.

\section{Results}

Of the 4087 tested patients with allergic contact dermatitis positive reactions to PPDA and other aromatic amines were found in 166 (4.06\%) individuals: 120 women (aged 12-88 years) and 46 men (aged 15-77 years). Sociodemographic and clinical characteristics are shown in Table I. Allergy to amines was significantly more common in urban habitants $(72 \%)$ than in rural dwellers $(p=0.031)$. A reliable association between skin lesions and occupational work was established in $25 \%$ of women and in $58.7 \%$ of men $(p<0.0001)$, whereas a probable relationship was found in $9.2 \%$ of women and $15 \%$ of men. The duration of dermatitis varied from 1 month to 35 (mean: 4.23) years in women and 
Table I. Sociodemographic and clinical data of patients with positive patch test reactions to PPDA and derivatives

\begin{tabular}{|c|c|c|c|c|}
\hline Parameter & Total & Female & Male & $P$-value \\
\hline Total number of patients (\%) & $4087(100)$ & $2730(66.8)$ & $1357(33.2)$ & $<0.001$ \\
\hline Number of positive results (\%) & $166(4.06)$ & $120(4.4)$ & $46(3.4)$ & 0.126 \\
\hline Sex, $n(\%)$ & $166(100)$ & $120(72.3)$ & $46(27.7)$ & $<0.0001$ \\
\hline \multicolumn{5}{|l|}{ Age [years]: } \\
\hline Mean & $43.27 \pm 16.4$ & $41.54 \pm 15.8$ & $46.22 \pm 18.7$ & 0.1070 \\
\hline Range & $12-88$ & $12-88$ & $15-77$ & \\
\hline Social background, rural/urban, $n$ (\%) & $\begin{array}{c}45 / 121 \\
(27.1 / 72.9)\end{array}$ & $\begin{array}{c}27 / 93 \\
(22.5 / 77.5)\end{array}$ & $\begin{array}{c}18 / 28 \\
(39.1 / 60.9)\end{array}$ & $0.031^{\#}$ \\
\hline \multicolumn{5}{|l|}{ Association with occupational work (\%): } \\
\hline Proven & $57(34.3)$ & $30(25)$ & $27(58.7)$ & $<0.0001^{\#}$ \\
\hline Possible & $18(10.8)$ & $11(9.2)$ & $7(15.2)$ & 0.26 \\
\hline Not associated & $91(54.8)$ & $79(65.8)$ & $12(26.1)$ & $<0.0001^{\#}$ \\
\hline \multicolumn{5}{|l|}{ Disease duration [years]: } \\
\hline Mean & $4.12 \pm 5.4$ & $4.23 \pm 5.87$ & $3.83 \pm 4.23$ & 0.7266 \\
\hline Range & $0.1-35$ & $0.1-35$ & $0.2-22$ & \\
\hline Atopy, in family/in patient, $n$ (\%) & $\begin{array}{c}50 / 61 \\
(30.1 / 36.7)\end{array}$ & $\begin{array}{c}39 / 50 \\
(32.5 / 41.7)\end{array}$ & $\begin{array}{c}11 / 11 \\
(23.9 / 23.9)\end{array}$ & $0.27 / 0.03^{\#}$ \\
\hline \multicolumn{5}{|l|}{ Clinical characteristics, $n$ (\%): } \\
\hline Hand dermatitis & $56(33.1)$ & $42(35)$ & $14(30.4)$ & 0.5747 \\
\hline Disseminated eczema & $47(28.3)$ & $31(25.8)$ & $16(34.8 \%)$ & 0.249 \\
\hline Facial dermatitis & $27(16.3)$ & $26(21.7)$ & $1(2.2)$ & $0.0023^{\#}$ \\
\hline Hands and feet dermatitis & $16(9.6)$ & $8(6.7)$ & $8(17.4)$ & $0.0368^{\#}$ \\
\hline Feet dermatitis & $4(2.4)$ & $2(1.7)$ & $2(4.3)$ & 0.329 \\
\hline Leg eczema & $7(4.2)$ & $3(2.5)$ & $4(8.7)$ & 0.07 \\
\hline Eczema of other body areas & $5(3.0)$ & $5(4.2)$ & 0 & 0.158 \\
\hline Urticaria & $2(1.2)$ & $2(1.7)$ & 0 & 0.373 \\
\hline Erythema multiforme-like lesions & $1(0.6)$ & 0 & $1(2.2)$ & 0.485 \\
\hline
\end{tabular}

"Statistically significant, $p<0.05$.

from 2 months to 22 (mean: 3.83) years in men. Personal history of atopy was reported by $36.7 \%$ of those examined: $41.7 \%$ female and $23.9 \%$ male ( $p=0.03$ ). In $98 \%$ of the study patients allergy to PPDA and other amines presented as contact eczema, usually affecting hands (33.1\%), and disseminated eczema (28.3\%). The facial skin was involved in $16.3 \%$ of patients, significantly more frequently in women ( $p=0.0023$ ) (Figure 1); hand and foot dermatitis was diagnosed in $9.6 \%$, more frequently in men $(p=0.037)$.

Positive patch test reactions to particular amines and their intensity are shown in Table II. Positive reactions to PPDA were found in 128 (77.1\%) patients, to IPPD in 34 (20.5\%) cases, more frequently in men $(p=0.032)$. Reactions to TDA were seen in 10 women, to EDA and TETA only in men. Benzocaine gave positive reactions in 18 individuals with equal frequency in males and females, paraben mix in 8 patients, significantly more frequently in men $(p=0.024)$.

Weakly positive reactions (+) were observed in $47.4 \%$ (PPDA) to $75 \%$ (paraben mix) of patients, strongly positive reactions (++) from $11.8 \%$ (IPPD) to $50 \%$ (TDA), extreme reactions from $25.8 \%$ (PPDA) to 33.3\% (benzocaine).

The relationship between allergy to PPDA and occupational activity is presented in Table III. Of 128 individuals allergic to PPDA, a reliable or probable association of dermatitis with occupational 
Table II. Positive patch test reactions to the respective aromatic amines, other chemicals cross-reacting to PPDA and the reaction grade

\begin{tabular}{|c|c|c|c|c|c|c|c|}
\hline \multirow[t]{2}{*}{ Allergen } & \multicolumn{4}{|c|}{ Number $(\%)^{*}$ of positive results } & \multicolumn{3}{|c|}{$\begin{array}{l}\text { Reaction grade, } n \text { total }(\%)^{* *} \\
(\mathrm{~F} / \mathrm{M})\end{array}$} \\
\hline & $\begin{array}{l}\text { Total } \\
N=166\end{array}$ & $\begin{array}{l}\text { Female } \\
n=120\end{array}$ & $\begin{array}{l}\text { Male } \\
n=46\end{array}$ & $P$-value & + & ++ & +++ \\
\hline PPDA & $128(77.1)$ & $94(78.3)$ & $34(73.9)$ & 0.54 & $\begin{array}{c}53(41.4) \\
(35 / 18)\end{array}$ & $\begin{array}{c}42(33.0) \\
(32 / 10)\end{array}$ & $\begin{array}{c}33(25.8) \\
(27 / 5)\end{array}$ \\
\hline IPPD & $34(20.5)$ & $17(14.2)$ & $17(36.9)$ & 0.032 & $\begin{array}{c}21(61.7) \\
(16 / 5)\end{array}$ & $\begin{array}{c}4(11.8) \\
(1 / 3)\end{array}$ & $\begin{array}{c}9(26.5) \\
(0 / 9)\end{array}$ \\
\hline TDA & $10(6.0)$ & $10(8.3)$ & 0 & 0.0002 & $\begin{array}{l}5(50) \\
(5 / 0)\end{array}$ & $\begin{array}{l}5(50) \\
(5 / 0)\end{array}$ & 0 \\
\hline TETA & $2(1.2)$ & 0 & $2(4.3)$ & 0.315 & $\begin{array}{c}2(100) \\
(0 / 2)\end{array}$ & 0 & 0 \\
\hline EDA & $1(0.6)$ & 0 & $1(2.15)$ & 0.487 & 0 & 0 & $1(0 / 1)$ \\
\hline Paraben mix & $8(4.8)$ & $3(2.5)$ & $5(10.9)$ & 0.024 & $\begin{array}{l}6(75) \\
(2 / 4)\end{array}$ & $\begin{array}{c}2(100) \\
(1 / 1)\end{array}$ & 0 \\
\hline Benzocaine/Caine mix & $18(10.8)$ & $13(10.8)$ & $5(10.9)$ & 0.99 & $\begin{array}{c}7(38.9) \\
(6 / 1)\end{array}$ & $\begin{array}{c}5(27.8) \\
(4 / 1)\end{array}$ & $\begin{array}{c}6(33.3) \\
(3 / 3)\end{array}$ \\
\hline
\end{tabular}

${ }^{\star}$ Percentage calculated in relation to the total number of patients with positive patch tests (total, F, M), ${ }^{* *}$ percentage calculated in relation to the total number of patients with positive patch test reactions to a respective allergen. PPDA - paraphenylenediamine, IPPD - N-isopropyl$\mathrm{N}$-phenyl-4-phenylenediamine, TDA - toluene-2,5-diamine, TETA - triethylenetetramine, EDA - ethylenediamine.

work was noted in $100 \%$ of mechanics, hairdressers, $81 \%$ of farmers, $75 \%$ of building constructors, $66 \%$ of those having contact with printing ink and $50 \%$ of food service workers. In the remaining patients allergy to PPDA developed in everyday conditions.

The association of IPPD allergy with occupation is shown in Table IV. Among the 34 patients allergic to IPPD the only occupational character of skin lesions was found in farmers, mechanics, plumbers (total 11 patients) and in a hairdresser, a drainage engineer, a patient who had professional contact with printing ink and a worker operating an injection molding machine. Allergy to black rubber developed in everyday conditions in all pensioners and the majority of (5 out of 6 ) office employees, in a health care worker and a student.

Allergy to PPDA coexisted most frequently with positive reactions to benzocaine (17 cases) and IPPD (10 individuals). Simultaneous reactions to two para group chemicals were found in 23 patients, to 3 chemicals in 7 , and to 4 allergens in 1 patient (Table V).

The presence of positive patch test reactions to other cross-reacting chemicals depending on the intensity of the patch test reaction in PPDA-allergic patients are given in Table VI. Only $11.7 \%$ of patients with a weak reaction to PPDA, assessed as + , reacted to 1 additional compound, whereas $20 \%$ of individuals with a strong reaction $(++)$ and $30.3 \%$ with extremely positive reactions reacted to other chemicals ( $p=0.0348$ )

The presence of concurrent hypersensitivity to other cross-reacting chemicals in PPDA-patch

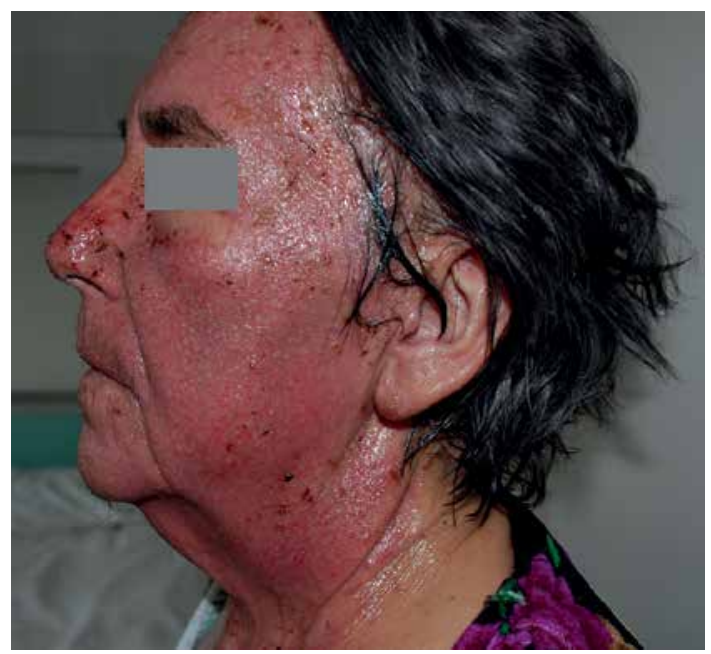

Figure 1. One of the women with contact dermatitis due to paraphenylenediamine after hair dye use

test-positive patients depending on the reaction intensity to PPDA is shown in Table VII. In patients with an extremely strong reaction to PPDA, reactions to benzocaine were observed significantly more frequently when compared to those showing a weak reaction $(p=0.013)$.

\section{Discussion}

Positive patch test results to $p$-phenylenediamine have been found in $4.06 \%$ of patients with allergic contact dermatitis, putting this outcome somewhere between the highest and the lowest re- 
Table III. Relationship between positive patch test reactions to PPDA and occupational work

\begin{tabular}{|lccc|}
\hline Occupation, $N=128$ & RR, $n(\%)$ & PR, $n(\%)$ & NR, $n$ (\%) \\
\hline Office worker, $N=24$ & $1(4.0)$ & 0 & $23(96.0)$ \\
\hline Farmer, $N=16$ & $13(81.0)$ & 0 & $3(19.0)$ \\
\hline Hairdresser, $N=8$ & $7(88.0)$ & $1(12.0)$ & 0 \\
\hline Health care employee, $N=9$ & $1(11.0)$ & $2(22.0)$ & $6(67.0)$ \\
\hline Occupational contact with ink, $N=9$ & $4(44.0)$ & $2(22.0)$ & $3(33.0)$ \\
\hline Mechanic, $N=3$ & $2(67.0)$ & $1(33.0)$ & 0 \\
\hline Food service worker, $N=4$ & $2(50.0)$ & 0 & $2(50.0)$ \\
\hline Construction worker, $N=8$ & $5(62.5)$ & $1(12.5)$ & $2(25.0)$ \\
\hline Student, $N=12$ & 0 & 0 & $12(100)$ \\
\hline Housewife, $N=7$ & 0 & 0 & $7(100)$ \\
\hline Seller, $N=6$ & $2(33.0)$ & $1(17.0)$ & $3(50.0)$ \\
\hline Retiree, $N=4$ & $1(25.0)$ & 0 & $3(75.0)$ \\
\hline Cleaner, $N=3$ & $2(67.0)$ & $1(33.0)$ & 0 \\
\hline Occupational contact with textiles, $N=3$ & 0 & $1(33.0)$ & $2(67.0)$ \\
\hline Policeman, $N=2$ & $1(50.0)$ & 0 & $1(50.0)$ \\
\hline Computer scientist, $N=2$ & $1(50.0)$ & $1(50.0)$ & 0 \\
\hline Others* $N=8$ & $5(62.5)$ & $1(12.5)$ & $2(25)$ \\
\hline
\end{tabular}

${ }^{*}$ These include: drainage engineer, customs officer, missionary, beauty salon worker, cashier, worker operating the injection molding machine, municipal sanitation worker, carpenter, $N$ - number of individuals allergic to PPDA, NR - no relation to occupational work, PR - probable relation to occupational work, $R R$ - reliable relation to occupational work.

Table IV. Relationship between IPPD allergy and occupational work

\begin{tabular}{|lccc|}
\hline Occupation, $N=34$ & RR, $n(\%)$ & PR, $n$ (\%) & NR, $n$ (\%) \\
\hline Farmer, $N=6$ & $6(100)$ & 0 & 0 \\
\hline Mechanic, $N=3$ & $3(100)$ & 0 & 0 \\
\hline Hairdresser, $N=1$ & $1(100)$ & 0 & 0 \\
\hline Customs officer, $N=1$ & $1(100)$ & 0 & 0 \\
\hline Plumber, $N=2$ & $2(100)$ & 0 & 0 \\
\hline Food service worker, $N=2$ & $1(50.0)$ & $1(50.0)$ & 0 \\
\hline Occupational contact with textiles, $N=1$ & 0 & $1(100)$ & 0 \\
\hline Occupational contact with ink, $N=1$ & $1(100)$ & 0 & 0 \\
\hline Drainage engineer, $N=1$ & $1(100)$ & $1(100)$ & $5(83.0)$ \\
\hline Forester, $N=1$ & 0 & $1(17.0)$ & 0 \\
\hline Office worker, $N=6$ & 0 & 0 & $1(100)$ \\
\hline Worker operating the injection molding machine, $N=1$ & $1(100)$ & 0 & $1(100)$ \\
\hline Student, $N=1$ & 0 & 0 & 0 \\
\hline Health care employee, $N=1$ & 0 & $1(100)$ & $4(100)$ \\
\hline Construction worker, $N=1$ & 0 & 0 & 0 \\
\hline Retiree, $N=4$ & 0 & $1(100)$ & 0 \\
\hline Driver, $N=1$ & $N=1000$ & 0 \\
\hline
\end{tabular}

$N$-number of individuals allergic to IPPD, $N R$ - no relation to occupational work, $P R$ - probable relation to occupational work, $R R-r e l i a b l e$ relation to occupational work. 
Table V. Cross-reactions in patients allergic to PPDA and other chemicals of the para group

\begin{tabular}{|lccc|}
\hline Allergens & Total, $N$ & Female, $n$ & Male, $n$ \\
\hline PPDA & 100 & 81 & 19 \\
\hline IPPD & 23 & 16 & 7 \\
\hline TDA & 9 & 9 & 1 \\
\hline EDA & 1 & 0 & 1 \\
\hline TETA & 1 & 1 & 5 \\
\hline PPDA + IPPD & 6 & 1 & 2 \\
\hline PPDA + paraben mix & 3 & 8 & 1 \\
\hline PPDA + benzocaine & 11 & 0 & 2 \\
\hline PPDA + benzocaine + epoxy & 1 & 1 & 0 \\
\hline PPDA + paraben mix + benzocaine & 3 & 1 & 0 \\
\hline TDA + epoxy & 1 & 1 & 1 \\
\hline PPDA + IPPD + benzocaine & 1 & 0 & 1 \\
\hline PPDA + IPPD + paraben mix & 1 & 0 & 1 \\
\hline PPDA + IPPD + paraben mix + benzocaine & 1 & 0 & 1 \\
\hline PPDA + IPPD + TETA & 1 & 0 & 0 \\
\hline IPPD + paraben mix & 1 & 0 & 1 \\
\hline IPPD + benzocaine & 1 & 0 & 1 \\
\hline
\end{tabular}

$n$-number of patients with positive patch test results, PPDA - paraphenylenediamine, IPPD - N-isopropyl- $N$-phenyl-4-phenylenediamine, TDA - toluene-2,5-diamine, TETA - triethylenetetramine, EDA - ethylenediamine.

Table VI. Positive patch test reactions to other chemicals of the para group in individuals with primary allergy to PPDA depending on patch test reaction grade

\begin{tabular}{|c|c|c|c|c|c|c|c|}
\hline & \multirow{2}{*}{$\begin{array}{l}\text { Grade of } \\
\text { reaction to } \\
\text { PPDA }\end{array}$} & \multirow{2}{*}{$\begin{array}{l}\text { Primary } \\
\text { allergy to } \\
\text { PPDA total, } \\
N=124\end{array}$} & \multirow{2}{*}{$\begin{array}{c}\text { Only PPDA, } \\
N=100, n(\%)\end{array}$} & \multicolumn{4}{|c|}{ PPDA + other para group chemicals, $N=24$} \\
\hline & & & & $\begin{array}{c}1 \text { allergen, } \\
N=16\end{array}$ & $\begin{array}{c}2 \text { allergens, } \\
\qquad \begin{array}{c}N=7\end{array}\end{array}$ & $\begin{array}{c}3 \text { allergens, } \\
\quad N=1\end{array}$ & $\begin{array}{l}\text { Total, } \\
n(\%)\end{array}$ \\
\hline 1 & + & 51 & $45(88.2)$ & 6 & 0 & 0 & $6(11.7)$ \\
\hline 2 & ++ & 40 & $32(80.0)$ & 6 & 2 & 0 & $8(20)$ \\
\hline \multirow[t]{2}{*}{3} & +++ & 33 & $23(69.7)$ & 4 & 5 & 1 & $10(30.3)$ \\
\hline & & & NS & NS & $\begin{array}{c}1 \text { vs. } 3 \\
p=0.042\end{array}$ & $\begin{array}{c}1 \text { vs. } 3 \\
p=0.2187\end{array}$ & $\begin{array}{c}1 \text { vs. } 3 \\
p=0.0348\end{array}$ \\
\hline
\end{tabular}

$N$ - number of patients with positive patch test results, PPDA - paraphenylenediamine.

Table VII. Relationship between cross-reactions to other para-group chemicals and the grade of patch test reactions to PPDA

\begin{tabular}{|c|c|c|c|c|c|c|c|c|}
\hline & \multicolumn{2}{|c|}{ Positive reactions to PPDA } & \multicolumn{6}{|c|}{ Positive reactions to other para group compound, $N(\%)^{*}$} \\
\hline & $\begin{array}{l}\text { Grade of } \\
\text { reaction to PPDA }\end{array}$ & $\begin{array}{c}N \\
N=128\end{array}$ & $\begin{array}{l}\text { IPPD } \\
N=10\end{array}$ & $\begin{array}{c}\text { TDA } \\
N=0\end{array}$ & $\begin{array}{c}\text { EDA } \\
N=0\end{array}$ & $\begin{array}{l}\text { TETA } \\
N=1\end{array}$ & $\begin{array}{l}\text { Paraben mix } \\
\qquad N=8\end{array}$ & $\begin{array}{c}\text { Benzocaine } \\
\quad N=18\end{array}$ \\
\hline 1 & + & 53 & $3(5.7)$ & 0 & 0 & $1(1.9)$ & $3(5.6)$ & $4(7.5)$ \\
\hline 2 & ++ & 42 & $4(9.5)$ & 0 & 0 & 0 & $3(7.1)$ & $5(11.9)$ \\
\hline \multirow[t]{2}{*}{3} & +++ & 33 & $3(9.4)$ & 0 & 0 & 0 & $2(6.4)$ & $9(27.3)$ \\
\hline & & & NS & & & NS & NS & $\begin{array}{c}1 \text { vs. } 3 \\
p=0.013^{\#}\end{array}$ \\
\hline
\end{tabular}

*Percentage calculated in relation to the total number of positive reactions to PPDA of the respective grade. PPDA - paraphenylenediamine, IPPD - N-isopropyl-N-phenyl-4-phenylenediamine, TDA - toluene-2,5-diamine, TETA - triethylenetetramine, EDA - ethylenediamine. 
sults obtained in other European countries [12-15]. However, Thyssen et al. showed considerable variance in the frequency of allergies to PPDA in various European countries: lower in Scandinavia and higher in Central and Southern Europe [10]. An even higher percentage of people allergic to PPDA can be seen in the United States (up to 7\%), [10] and in Asia (11.5-12.8\%) [16, 17].

An analysis of the demographic data of patients participating in the study showed a similar frequency of positive reactions to PPDA in both women and men suffering from dermatitis. The average age as well as the length of the disease also did not significantly differ between the sexes. An allergy to PPDA was found much more often in urban areas, especially in women, in line with the results of other studies $[18,19]$. This fact may be related to the growing number of hairdressing and beauty salons as well as the recently fashionable tattoo parlors. Correlation of PPDA allergies with professional activity occurred twice as often in men, probably as the result of varying sources of PPDA allergies for both sexes $[20,21]$. It is also interesting that over one third of all patients allergic to PPDA, especially women $(41.7 \%)$, reported a personal history of atopy. The overrepresentation of atopic individuals may result from increased skin permeability in these patients. The diverse pattern of sensitization in both sexes seems to be related to differences in exposure to allergen in occupational and household conditions. The prevalence of women among atopic patients allergic to PPDA can be explained by the extensive use of cosmetics including hair dyes, permanent makeup and tattoos in this sex group. There is controversy regarding the influence of intrinsic sex-dependent factors on the development and course of ACD [22, 23]. Estradiol and progesterone have been shown to enhance IgE-dependent allergic reactions in mice [24], but it is unclear whether these hormones have a similar influence on delayed type of hypersensitivity.

Paraphenylenediamine can cause reactions which differ clinically but most often occur as allergic contact dermatitis. This substance is a colorless precursor of the permanent hair dye which itself is not protein reactive and needs to be oxidized to form colorful complexes during the hair dying procedure. A small amount of PPDA which has not been oxidized can auto-oxidize on the skin to form derivatives which can irreversibly bind to different proteins, leading to diverse hapten-protein complexes [25-27]. These oxidation products are shown to be potent sensitizers [28].

Skin changes resulting from PPDA causing immediate reactions such as urticaria, angioedema and anaphylaxis are seldom seen, with erythema multiforme-like lesions [29-31], lichenoid eruption
[32] and pseudolymphoma [33] being even more rare. In the majority of patients, the allergy to PPDA presented as dermatitis, most often of the hands (31.1\%) and disseminated eczema (28.3\%), with a similar frequency in men and women. Eczema of the face significantly predominated in women $(21.7 \%)$, which was associated with allergic reactions to hair dyes. In research carried out on a group of patients with dermatitis caused by hair dyes conducted by Ho et al. the skin of the face and neck was affected in $28 \%$ of patients, hands and arms in 25\%, and disseminated eczema was seen in $17 \%$ of individuals [34].

Two of the patients taking part in the current study who were allergic to PPDA had urticaria and one patient presented skin lesions similar to erythema multiforme. The IgE-dependent mechanism of allergy to PPDA has not been fully explained. The IgE specific to PPDA or any related oxidative products have not been found in vitro yet, but positive prick test with PPDA in a patient who underwent anaphylactic shock due to PPDA exposure has been described [29]. PPDA is absorbed through the skin, where it is acetylated to $N$-mono and $N, N$-diacetylated metabolites, and a small amount of PPDA is auto-oxidized. The oxidative products bind to cysteine on human serum albumin, turning to complete antigen [25, 26]. It is unclear whether the IgE is directed against a chemical compound or toward albumin modified by a PPDA derivative. Additionally, immunohistopathological examinations in humans and mice revealed the presence of PPDA-specific T cell subpopulations secreting Th2 cytokines in the infiltrations of skin lesions [25].

Among study participants most people were allergic to paraphenylenediamine - the main allergen detecting allergies to aromatic amines included in the basic series of contact allergens. Hair dyes are the biggest source of PPDA causing allergic reactions in beauty salon customers as well as hairdressers and beauticians [35]. In the customers these dermatological changes appeared on the skin of the head and neck while in hairdressers hands and forearms were affected. Those who colored their hair at home developed lesions in both locations mentioned above. In our patients, allergies to PPDA occurred more often in women, although the difference was not significant. Dermatitis involved mainly the regions of the head and neck, while the lesions appearing on the hands and forearms were associated with professional activity of hairdressers or professional contact with printing ink.

A certain or possible association of the skin lesions with occupation was found in all mechanics, most hairdressers, farmers, construction workers and people having contact with printing ink as well as in half of food industry workers. Allergies 
to aromatic amines in patients belonging to the remaining groups developed in everyday life conditions. Plant-based pigments, such as henna or fabric dyes, may also contain paraphenylenediamine. Henna is a natural colorant obtained from the leaves of Lawsonia inermis. The staining agent contained in henna is 2-hydroxy-1,4-naphthoquinone. It is a weak allergen but when enhanced with PPDA, which is often the case, it can become the cause of allergic reactions resulting from hair dying and tattooing. Chromatographic analyses of 25 black henna tattoo samples available for sale in Turkey showed the presence of PPDA ranging from $3.37 \%$ to $51.6 \%$ [36]. Fabric dyes used in clothing turned out to be the most common sources of allergies for women with disseminated eczema (data not shown).

Allergies to IPPD more often affected men than women. $\mathrm{N}$-isopropyl- $N$-phenyl-4-phenylenediamine is used as an antioxidant in the process of technical, mainly black, rubber vulcanization. The sources of allergies include rubber items such as tires, shoes, protective masks, rubber hoses or gaskets. Occupation-related allergies to IPPD most often concern people involved in the vulcanization process, mechanics, farmers as well as drivers [37], which was also observed in our study. However, in 9 of the 17 women allergic to IPPD the allergy was not related to their occupation and was caused by contact with rubber or textiles (data not shown).

Positive test results to TDA were recorded only in women. Of 10 patients allergic to this substance two hairdressers had lesions on their hands and forearms, as a result of their occupational activity. In the remaining eight female patients the changes, appearing after hair dying, were located on the face and neck. However, none of them showed positive reactions to PPDA. Dyes containing TDA are labeled as "PPDA-free" and are considered to be an alternative for people allergic to PPDA. However, allergies to both these substances can occur simultaneously [38-40].

Ethylenediamine (EDA) is a compound used for the production of epoxy resins, coolants, fungicides and insecticides, as well as fabrics, but is also an ingredient of photo developers and deicing agents. Only one participant of our study, with lesions on his hands and forearms, an industrial equipment installer, was allergic to this compound. This allergen is included in a series of cosmetics and resins.

Triethylenetetramine or TETA is a hardener in epoxy resins. Two men had positive reactions to this allergen: an injector operator and a farmer. The latter patient additionally showed a very strong reaction to IPPD $(+3)$ and PPDA $(+1)$ (data not shown), indicating the secondary character of sensitization to TETA.
Within the group of study participants, the allergy to benzocaine was noted in over $10 \%$ of individuals allergic to amines, with a similar frequency in men and women. Benzocaine is an ethyl ester of paraaminobenzoic acid (PABA). It is used as a dermatological and dental topical anesthetic, an injected local anesthetic and for the treatment of burns, hemorrhoids and painful changes in mucous membranes. Benzocaine can cause crossreactions with other anesthetics from the same group of caines such as procaine, lidocaine, tetracaine, propoxycaine, dibucaine, as well as with paraphenylenediamine and its derivatives and other compounds from this para group [41].

Paraaminobenzoic acid esters (parabens, aseptin) used as preservatives in the production of cosmetics, medicine and food products are generally considered to be mild allergens. Reactions to parabens were observed in $4.8 \%$ of patients with allergy to aromatic amines. Most frequently these reactions were weakly "+" and always accompanied by a stronger reaction to aromatic amines, indicating a secondary character of the allergy. A mix of paraaminobenzoic acid esters (methyl, ethyl, propyl and butyl) or paraben mix included in the baseline series of allergens is used to detect allergies.

Paraphenylenediamine may exhibit cross-allergen reactions with other compounds belonging to the para group. Occurrence of simultaneous reactions with other chemicals of the para group can result from cross-reaction due to structural similarity of the allergen with PPDA or is an independently developing allergic reaction to a given chemical. Cross-reactivity is defined as allergy to a chemical with a related structure, to which the person has yet not been exposed. Differentiation between cross-reaction and co-sensitization can be difficult [42]. It is unclear whether some people are genetically predisposed to development of contact allergy to certain chemicals. A molecular study suggested that polymorphism in genes encoding cytokines or metabolizing PPDA enzymes in the skin might have an influence on the mechanism of sensitization. It has been shown that slow acetylator patients are more predisposed to contact sensitization [43]. Of the individuals allergic to PPDA 28 (21.8\%) showed cross-reactions with one or more related chemicals. Compounds which cross-react with PPDA include other aromatic amines, para-aminobenzoic acid and its derivatives, azo dyes, sulfonamides, benzocaine, and para-aminosalicylic acid [42, 44]. Contact with compounds having similar chemical structure may lead to recurrence of the disease. Crossreactions to other allergens of the para group occurred significantly more often in patients with the strongest patch test reactions to paraphenylenediamine, assessed at “+++", in comparison to 
people exhibiting a weak reaction to PPDA. This is consistent with the observations made by Thomas, who observed a correlation between a strong reaction to PPDA and a greater number of crossreacting compounds [45].

Cross-reactions to benzocaine/caine mix were observed significantly more often in people having a strong reaction to PPDA, assessed at "+++", $(p=0.013)$. No correlation was found between cross-reactions with other compounds belonging to the para group and the intensification of the reaction to PPDA.

The positive patch test results with other contact allergens found in our patients were not considered in the analysis. We focused only on allergens belonging to the para group in order not to complicate the issue. It may however be a limitation of this study. Skin inflammation developing during allergic reaction to one allergen increases the risk of acquisition of allergy to another sensitizer.

In conclusion, the high level of intensification of PPDA hypersensitivity increases the risk of allergies to other compounds of the para group. To prevent the development of new allergies it is important to educate the population, young people in particular, about the potential risk of allergy to paraphenylenediamine and subsequent health consequences.

\section{Conflict of interest}

The authors declare no conflict of interest.

\section{References}

1. Commission Directive 2009/130/EC amending Council Directive 76/768/EEC, concerning cosmetic products, for the purpose of adapting Annex III thereto to technical progress. https://eur-lex.europa.eu/LexUriServ/LexUriServ.do?uri=OJ:L:2009:268:0005:0008:EN:PDF.

2. Sosted H, Johansen JD, Andersen KE, Menne T. Severe allergic hair dye reactions in 8 children. Contact Dermatitis 2006; 54: 87-91.

3. Pasche-Koo E, French L, Piletta-Zanin PA, Hauser C. Contact urticaria and shock to hair dye. Allergy 1998; 53: 904-5.

4. Belton AL, Chira T. Fatal anaphylactic reaction to hair dye. Am Forensic Med Pathol 1997; 18: 290-2.

5. Anuradha S, Arora S, Mehrotra S, Arora A, Kar P. Acute renal failure following para-phenylenediamine (PPD) poisoning: a case report and review. Renal Failure 2004; 26: 329-32.

6. Armstrong DK, Jones AB, Smith HR, et al. Occupational sensitization to $p$-phenylenediamine: a 17-year review. Contact Dermatitis 1999; 41: 348-9.

7. Bordel-Gomez MT, Miranda-Romero A, CastrodezaSans J. Epidemiology of contact dermatitis: prevalence of sensitization to different allergens and associated factors. Actas Dermosifiliogr 2010; 101: 59-75.

8. McFadden JP, Yeo L, White JL. Clinical and experimental aspects of allergic contact dermatitis to paraphenylenediamine. Clin Dermatol 2011; 29: 316-24.

9. Uter W, Lessmann H, Geier J, Schnuch A. Contact allergy to ingridients of hair cosmetics in faemale hairdressers and clients - an 8-year analysis of IVDK data. Contact Dermatitis 2003; 43: 3110-3.

10. Thyssen JP, Andersen KE, Bruze M, et al. Phenylenediamine sensitization is more prevalent in central and southern European patch test centres than in Scandinavian: results from a multicentre study. Contact Dermatitis 2009; 60: 314-9.

11. Kieć-Świerczyńska M, Kręcisz B, Świerczyńska-Machura D. Rosnąca rola alergii zawodowej i pozazawodowej na parafenylenodiaminę. Med Pr 2007; 58: 131-7.

12. Patel S, Basketter DA, Jefferies D, et al. Patch test frequency to $p$-phenylenediamine: follow up over the last 6 years. Contact Dermatitis 2007; 56: 35-7.

13. Sosted H, Rustemeyer T, Goncalo M, et al. Contact allergy to common ingredients in hair dyes. Contact Dermatitis 2013; 69: 32-9.

14. Ponyai G, Diczig BM, Nemeth I, Temesvari E. Para-phenylenediamine hypersensitivity: a report from Budapest, Hungary, 2007-2014. Dermatitis 2016; 27: 303-7.

15. Schuttelaar ML, Vogel TA, Rui F, et al. ESSCA results with the baseline series, 2002-2012: p-phenylenediamine. Contact Dermatitis 2016; 75: 165-72.

16. Sharma VK, Chakrabarti A. Common contact sensitizers in Chandigarh, India. A study of 200 patients with the European standard series. Contact Dermatitis 1998; 38: 127-31.

17. Li LF, Guo J, Wang J. Environmental contact factors in eczema and the results of patch testing Chinese patients with a modified European standard series of allergens. Contact Dermatitis 2004; 51: 22-5.

18. Gupta M, Mahajan VK, Mehta KS, Chauhan PS. Hair dye dermatitis and $\mathrm{p}$-phenylenediamine contact sensitivity: a preliminary report. Indian Dermatol Online J 2015; 6: 241-6.

19. Dogra A, Minocha YC, Caur S. Adverse reactions to cosmetics. Indian J Dermatol Venereol Leprol 2003; 69: 165-7.

20. Geier J, Lessmann H, Schnuch A, Uter W. Contact sensitizations in metalworkers with occupational dermatitis exposed to water-based metalworking fluids: results of the research project "FaSt". Int Arch Occup Environ Health 2004; 77: 543-51.

21. Fautz R, Fuchs A, van der Walle HB, Henny V, Smits L. Hair dye-sensitized hairdressers: the cross-reaction pattern with new generation hair dyes. Contact Dermatitis 2002; 46: 319-24.

22. Leyden JJ, Kligman AM. Allergic contact dermatitis: sex differences. Contact Dermatitis 1977; 3: 333-6.

23. Modjtahedi BS, Modjtahedi SP, Maibach HI. The sex of the individual as a factor in allergic contact dermatitis. Contact Dermatitis 2004; 50: 53-9.

24. Chen W, Mempel M, Schober W, Behrendt H, Ring J. Gender difference, sex hormones, and immediate type hypersensitivity reactions. Allergy 2008; 63: 1418-27.

25. Jenkinson $C$, Jenkins $R$, Aleksic $M$, Pirmohamed $M$ Naisbit D, Park BK. Characterization of paraphenylenediamine binding sites and T-cell responses to hapten modified protein. J investing Dermatol 2010; 110: 732-42.

26. Hueber-Becker F, Nohyneck G, Meuling W, Beneech-Keffer F, Toutain H. Human systemic exposure to 14-C-paraphenylenediamine containing exudative hair dye and correlation with in vitro percutaneous absorption in human or pig skin. Food Chem Toxicol 2004; 42: 1227-36.

27. Jahn S, Faber H, Zazzeroni R, Karts U. Electrochemistry/ liquid chromatography/mass spectrometry to demonstrate irreversibly binding of the skin alergen p-phenylenediamine to proteins. Rapid Commun Mass Spectrom 2012; 26: 1415-25. 
28. Young E, Zimerson E, Bruze M, Svedman C. Two sensitizing oxidation products of $p$-phenylenediamine patch tested in patients allergic to p-phenylenediamine. Contact Dermatitis 2016; 74: 76-82.

29. Helaskoski E, Suojalehto H, Virtanen H et al. Occupational asthma, rhinitis, and contact urticaria caused by oxydative hair dyes in hairdressers. Asthma Immunol 2014; 112:46-52.

30. Barrientos N, Abajo P, de Vega MM, Dominguez J. Erythema multiforme like eruption following allergic contact dermatitis response to para-phenylenediamine in a temporary henna tattoos. Int J Dermatol 2014; 53: 348-50.

31. Neri I, Giacomini F, Raone B, Patrizi A. Generalized erythema multiforme after localized allergic dermatitis from dark henna tattoo. Pediatr Dermatol 2009; 26: 496.

32. Rubegni P, Fimiani M, de Aloe G, Andreassi L. Lichenoid reaction to temporary tatoo. Contact Dermatitis 2000; 42: 117-8.

33. Calzavara-Pinton P, Capezzera R, Zane C, et al. Lymphomatoid allergic contact dermatitis from para-phenylenediamine. Contact Dermatitis 2002; 47: 173-4.

34. Ho SG, Basketter DA, Jefferies D, Rycroft RJ, White IR, McFadden JP. Analysis of parahenylenediamin allergic patients in relation to strength of patch test reaction. $\mathrm{Br}$ J Dermatol 2005; 153: 364-7.

35. Diepgen TL, Naldi L, Bruze M, et al. Prevalence of contact allergy to $\mathrm{p}$-phenylenediamine in the European general population. J Invest Dermatol 2016; 136: 409-15.

36. Sukkuroglu AA, Battal D, Burgas S. Monitoring of Lawsone, $p$-phenylenediamine and heavy metals in commercial temporary black henna tattoos sold in Turkey. Contact Dermatitis 2017; 76: 89-95.

37. Geier J, Lessmann H, Schnuch A, Uter W. Contact sensitizations in metalworkers with occupational dermatitis exposed to water-based metalworking fluids: results of the research project "FaSt". Int Arch Occup Environ Health 2004; 77: 543-51.

38. Jenkins D, Chow ET. Allergic contact dermatitis to para-phenylenediamine. Australas J Dermatol 2015; 56: 40-3.

39. Ingram JR, Hughes TM, Stone NM. Potential danger of hair dyes marketed as free from para-phenylenediamine. Int J Dermatol 2014; 53: e257-8.

40. Scheman A, Cha C, Bhinder M. Alternative hair-dye products for persons allergic to para-phenylenediamine. Dermatitis 2011; 22: 189-92.

41. Turchin I, Moreau L, Warshaw E, Sasseville D. Cross-reactions among parabens, para-phenylenediamine, and benzocaine: a retrospective analysis of patch testing. Dermatitis 2006; 17: 192-5.

42. Vogel TA, Heijnen RW, Coenraads PJ, Schuttelaar MA. Two decades of $p$-phenylenediamine and toluene-2,5-diamine patch testing - focus on co-sensitizations in the European baseline series and cross-reactions with chemically related substances. Contact Dermatitis 2017; 76: 81-8.

43. Blömeke B, Pietzsch T, Merk HF. Elicitation response characteristics to mono- and to $\mathrm{N}, \mathrm{N}^{\prime}$-diacetyl-para-phenylenediamine. Contact Dermatitis 2008; 58: 355-8.

44. Laberge L L, Pratt M, Fong B, Gavigan G. A 10-year review of $\mathrm{p}$-phenylenediamine allergy and related para-amino compounds at the Ottawa Patch Test Clinic. Dermatitis 2011; 22: 332-4.

45. Thomas BR, White IR, McFadden JP, Banerjee P. Positive relationship-intensity of response to $p$-phenylenediamine on patch testing and cross-reactions with related allergens. Contact Dermatitis 2014; 71: 98-101. 